\title{
An Anthropometric Comparison of Inner Canthal Distance, Outer Canthal Distance and Canthal Index in the Indian and Nepalese Undergraduate Students of Nepalgunj Medical College
}

\author{
Adhikari $\mathrm{N}^{1}$, Ambekar $\mathrm{MN}^{2}, \mathrm{KC} \mathrm{S}$
}

\begin{abstract}
Background: The canthal distances are one of the most important aspects in ascessing the facial aesthetics. Several authors have described changes in the canthal distances attributable to race and gender. Aims and Objectives: To compare the inner canntahl distance, outer canthal distance and canthal index in between Nepalese and Indian undergraduate students of Nepalgunj Medical College. Materials and Methods: The study was conducted to compare canthal distances and canthal index among 320 (160 Indians: 100 male, 60 female and 160 Nepalese: 100 male and 60 female) undergraduate students of Nepalgunj Medical College of age group 18-24 years at Department of Anatomy, Chisapani, Banke. Inner canthal distance(ICD) and Outer canthal Distance(OCD) were measured by using round end spreading caliper and Canthal Index were calculated by ICD/OCD *100. The value obtained was compared among Indian and Nepalese students in both sexes by using student $t$-test. Result: The study showed that there was no any significant difference on the value of inner and outer canthal distances and canthal index observed between Nepalese and Indian population except on the value of canthal index which was significantly different between Indian male and Nepalese male population. However, when the comparison was done between the sexes, inner and outer canthal distances and canthal index of males are larger than females except on the value of canthal index of Indian males and Indian females which was non-significant. Conclusion: There occurred a sexual dimorphism within Indian and Nepalese population except on canthal index of Indian male and Indian female but there wasn't any significant differences between Nepalese and Indian population of same sex except on canthal index of Indian male and Nepalese male.
\end{abstract}

Key words: Canthal index, inner canthal distance, outer canthal distance

\section{INTRODUCTION}

Anthropometry is the branch of anthropology concerned with measurements of the human body ${ }^{1}$. Over the centuries, there have been remarkable changes in Anthropometric measurements due to geographical, cultural, genetic and environmental factors ${ }^{2}$.

Canthus is the angle at either end of the fissure between the eyelids ${ }^{3}$. Lateral canthus is formed by the lateral part of superior and inferior eyelid and medial canthus is formed by the medial part of the superior and inferior eyelids. Canthal distances are measured as inner canthal distance and outer canthal distance. Inner canthal distance is the distance between the two medial canthi and outer canthal distance is the distance between the two lateral canthi ${ }^{4}$.

\footnotetext{
1. Dr. Nischita Adhikari

2. Prof. M.N. Ambekar

3. Dr. Sudikshya KC
}

Address for correspondence:

Dr. Nischita Adhikari

Department of Anatomy

Nepalgunj Medical College \& Teaching Hospital

Chisapani, Banke, Nepal

Email: nischita1985@gmail.com
Craniofacial anthropometry which deals with the measurements of skull also includes measurements of the inner and outer canthal distances and canthal index. It is important for the study of human growth and variations in different races and also for clinical diagnosis and treatment ${ }^{5}$. It has been reported earlier that people with different genetic background subjected to significantly different environmental influences have different craniofacial morphology ${ }^{6}$.

Nepalgunj medical college lies on Mid-Western region of Nepal. Approximately $40 \%$ of its students are holding the Indian Nationality. Only few reports are available on the above mentioned dimensions in Nepalese and Indian population. Hence the present work would be of great importance for comparison with the data analyzed by the earlier workers.

\section{MATERIALS AND METHODS}

The study was conducted in the department of Anatomy, Nepalgunj Medical College, Chisapani, Banke from April $17^{\text {th }}$ 2016 to October $20^{\text {th }} 2016$. The study comprised of total number of 320 (200 males and 120 females) healthy Nepalese and Indian students of Nepalgunj Medical College aged between $18-24$ years old (Table I).

Inclusion criteria: Indian and Nepalese Undergraduate medical students of Nepalgunj Medical College, Chisapani, Banke. 
Exclusion criteria: Students with any craniofacial defects and with clinical manifestation of telecanthus and epicanthus were excluded in the sample.

Each student were made to seat comfortably in a chair with the students head at the same level as approximately 40 centimeters in front of the examiner's head in a well illuminated room. A round end spreading caliper graduated in millimeters was used for the measurement of the canthal distances. The inner canthal distance was measured as the medial angle of the left eye to the medial angle of the right eye by having the subject look straight at the examiner while the spreading caliper was placed in between the bridge of the subject's nose. The outer canthal distance was measured as the distance from the lateral angle of the left eye to the lateral angle of the right eye instructing the subject to look upward to maximize the contrast between the sclera and the skin. Canthal index was then calculated as: inner canthal distance/outer canthal distance*100.

The statistical analysis was done firstly between the Male and Female of the same population and later on the analysis was performed between Nepalese and Indian students of same sex by using student t-test.

\begin{tabular}{|c|c|c|}
\hline NATIONALITY & MALE & FEMALE \\
\hline INDIAN & 100 & 60 \\
\hline NEPALESE & 100 & 60 \\
\hline
\end{tabular}

\section{RESULT}

The result obtained after the statistical analysis performed between male and female of same population (Indian or Nepalese) and again between Nepalese and Indian population of same sex by using independent ' $t$ ' test is given on Table II and Table III. All the parameters were taken in centimeters.

During comparison between males and females of same population (Table II), it was observed that all the values were higher in male than in female. Table II also showed statistically significant difference $(p<0.05)$ in all the parameters except Canthal Index between male and female of Indian population which was statistically non-significant ( $p>0.05)$.

Similarly, Table-III showed the comparison between Nepalese and Indian population of same sex which showed that there was statistically non-significant ( $p>0.05)$ difference between Nepalese and Indian population of same sex except Canthal Index of Nepalese male which was significantly higher than Indian male $(p<0.05)$.

\section{DISCUSSION}

There is a significant difference $(p<0.05)$ in the value of inner canthal distance, outer canthal distance and canthal index between male and female of Indian and Nepalese population with males having higher inner canthal distance and outer canthal distance than female except in the canthal index of Indian male and female which was non-significant ( $p>0.0 .5$ ).

Table I: Distribution of population with respect to sex and

\begin{tabular}{|l|c|c|c|c|}
\hline Parameters & Population & Mean \pm SD & & \\
\hline & & Male & Female & \\
\hline $\mathrm{ICD}$ & Indian & $3.31 \pm 0.37$ & $3.15 \pm 0.29$ & Significant \\
\hline & Nepalese & $3.37 \pm 0.33$ & $3.17 \pm 0.30$ & Significant \\
\hline $\mathrm{OCD}$ & Indian & $9.49 \pm 0.46$ & $9.13 \pm 0.33$ & Significant \\
\hline & Nepalese & $9.35 \pm 0.67$ & $9.15 \pm 0.35$ & Significant \\
\hline $\mathrm{CI}$ & Indian & $34.89 \pm 3.53$ & $34.52 \pm 2.87$ & Non-Significant \\
\hline & Nepalese & $36.30 \pm 5.65$ & $34.62 \pm 3.20$ & Significant \\
\hline
\end{tabular}

ICD=Inner Canthal Distance: $\mathrm{OCD}=$ Outer Canthal Distance: $\mathrm{Cl}=$ Canthal Index

Table II: Comparison of ICD, OCD and CI between male and female of same population

\begin{tabular}{|l|c|c|c|c|}
\hline \multicolumn{1}{|c|}{ Parameters } & Gender & Indian & Nepalese & \\
\hline ICD & Male & $3.31 \pm 0.37$ & $3.37 \pm 0.33$ & Non-Significant \\
\hline OCD & Female & $3.15 \pm 0.29$ & $3.17 \pm 0.30$ & Non-Significant \\
\hline & Male & $9.48 \pm 0.46$ & $9.35 \pm 0.66$ & Non-Significant \\
\hline $\mathrm{Cl}$ & Female & $9.13 \pm 0.33$ & $9.15 \pm 0.35$ & Non-Significant \\
\hline & Male & $34.89 \pm 3.53$ & $36.30 \pm 5.65$ & Significant \\
\hline
\end{tabular}

$I C D=$ Inner Canthal Distance: $O C D=$ Outer Canthal Distance: $\mathrm{Cl}=$ Canthal Index

Table III: Comparison of ICD, OCD and CI between Indian and Nepalese population of same sex 
However when the comparison was done between Nepalese and Indian population, there was non-significant differences ( $p>0.05$ ) except on the value of canthal index of male Indian and male Nepalese population which was significant ( $p>0.05)$.

The present study showed that inner and outer canthal distances of males are larger than those of females except on the canthal index of Indian males and females. The result of this study was similar with those of Cem et $\mathrm{al}^{7}$ (2001) on Turkish population, Erica et al $^{8}$ (2005) on Latvians, Oladipo et al $^{9}$ (2009) on Urhobo and Itsekiri of Nigeria, Oladipo et $\mathrm{al}^{10}$ (2011) on Ibibios of Nigeria, Osunwoke ${ }^{11}$ et al (2012) on ljaws of Nigeria. However the study conducted on Nepalese undergraduate medical students of BPKIHS, showed outer canthal distance and canthal index of male population was higher than female population but inner canthal distance was higher in female as compared to male population which was in contrast to our study $^{12}$.

When the comparison was done between Nepalese and Indian population there was no any significant differences found except on male canthal index between Nepalese and Indian Population. This study was in accordance with the study conducted on the comparison of vital capacity of Indian and Nepalese young female which showed no significant differences in the age, height, weight and body surface area between the group ${ }^{13}$. This may be due to the fact that Nepal is a neighboring country of India and the environmental factor, geographical distribution, food habit and culture, climatic effect, socioeconomic status of the people are quite similar with respect to Indian. The marriages are also common between Nepalese and Indian population.

\section{REFERENCES}

1. Donald RA, Doughlas RB, John B editors. Stedman's Medical Dictionary. $27^{\text {th }}$ ed. Philadelphia: Lippincott Williams and Wilkins; 1999. Anthropometry;p.95.

2. Irajuddin SM, Duggirala R, Craford MS. Population structure of Chenchu and other South Indian tribal groups: relationships between genetic, anthropometric, dermatoglyphic, geographic and linguistic distances. Human Biol. 1994 Oct.

3. Young $\mathrm{H}$, Health JW. Whealer's Functional Histology: Male Reproductive System. A text and colour atlas. $4^{\text {th }}$ Ed. New York: Churchill Livingstone; 2000.p.336.

4. Williams PL, Banister LH, Berry MM, Collins P, Dyson M, Dussek JE, Ferguson MWJ. Gray's Anatomy: Reproductive system. $38^{\text {th }}$ Ed. New York: Churchill Livingstone; p.1855-6.

5. Poswillo D. Casual mechanism for craniofacial deformity. J Trop pediatr.1963;44:973-977.

6. Kasai K, Richards LC, Brown T. Comparative study of craniofacial morphology in Japenese and Australian aboriginal Populations. Hum Biol. 1993;65(5):821-834.

7. Cem E, Cengiz Y, Hamdi E, Selim D, Yasar D. Normative values of craniofacial measurements in idiopathic benign microcephalic children. Cleft-palate Craniofac J. 2001;38(3):260-3.

8. Oladipo GS, Akande PA, Osogba IG, Yorkum KL. Anthropometric studies of inner canthal distance, outer canthal distance and canthal index of adult Ibibios. Asian J Med Sci. 2011;34(1):14-6.

9. Erica N, Uldis T, Dzintra K. Craniofacial anthropometry in a group of healthy Latvian residents. Acta Med Litu. 2005;12(1):47-53.

10. Oladipo GS, Fawehinmi HB, Okod PD. Canthal indices of Urhobo and Itsekiri ethnic groups. Aus J Basic Appl Sci. 2009;3(4):3093-6.

11. Osunwoke EA, Didia BC, Olotu EJ, Yerikema AH. A study on the normal values of inner canthal, outer canthal, interpupillary distance and head circumference of 3-21 years ljaws. Am J Sci Ind Res. 2012;3(6):441-5.

12. Shah S, Koirala S. Study of canthal index in Nepalese undergraduate medical students of Bpkihs, Nepal: gender and ethnic differences. J Kath Med Coll. 2014 Apr-Jun;3(2):78-81.

13. Chatterjee $P$, Das $P$, Debnath $P$, Banerjee KA. A comparative study of vital capacity of Indian and Nepalese young female. J Physic Educ Sport Manag. 2010 Aug;1(2):25-27. 